EPiC Series in Engineering
Volume 3, 2018, Pages 389-393
HIC 2018. 13th International
Conference on Hydroinformatics

\title{
Evaluation and stochastic simulation of storm precipitation for city underground utilities in condition of climate change.
}

\author{
Cavalli A.B. ${ }^{1}$, Ilinich V.V. ${ }^{1}$, Lapushkin M.Y. ${ }^{1}$, Naumova A.A. ${ }^{1}$ \\ ${ }^{1}$ Russian state agrarian university - Moscow agricultural academy \\ abcavalli1993@gmail.com
}

\begin{abstract}
.
The article is devoted to the modeling and estimation of the change in the maximum daily precipitation in the northern district of Moscow and the nearest Moscow suburbs against the background of changes in the average annual air temperatures and its average temperatures over the warm seasons. Special statistical methods used in hydrometeorology were used to assess changes. The obtained results indicate an increase in the calculated values of the hazardous precipitation and their occurrence frequency in the region during the last decades, which must be taken into account in the calculation of surface runoff for hydro- technical constructions and environmental objects. The special method of Monte-Carlo is offered for simulation of storm precipitation.
\end{abstract}

\section{Introduction}

Last half of century is observed a change of different climatic characteristics, in particularity daily maximum precipitations $[1,2,3,5,7$ and oth.], which are an element of water balance and has very significant impact at runoff of small city catchments. Majority of observation on the meteorological stations showed increasing of storm precipitation, but not always. So we have to check this hypothesis in respect to of the Moscow regions. Then there is need to simulate storm precipitation according to last time of observation series which has more short duration but more reality due to climate changes for consideration a big amount of different scenarios of storm precipitation, which have essential impact on the maximum runoff in city conditions. The main hypothesis of the study - the proposed method for simulation for scenarios of storm precipitation accurately in comparison with the statistical parameters of observed precipitation. So - the main statistic characteristics of the artificial long-time series should not differ substantially from similar characteristics of time series data for the last 30 years. 
Evaluation and Stochastic Simulation of Storm Precipitation for City Underground ....A. Cavalli et al.

\section{Methods and materials}

The studies were conducted on the base of data observation the meteorological station of the Russian Exhibition of National Economic Achievements. It is located in the northern district of Moscow and, it can be assumed, fairly objectively reflects the climatic characteristics and their changes in time relative to the region under consideration. This station is a very representative basis for the design of hydraulic structures and general construction sites. The researches based on data observation of daily precipitation from 1948 until 2013 years. 3 statistical rows were consisted. The first row involved maximum daily precipitation for every year. Second row contained all daily precipitation which exceed $30 \mathrm{~mm}$. Third row involved summa of precipitation during series days, the summa were more $50 \mathrm{~mm}$, total amount of such members of the row was 42. Every such series was represented by ratios of every daily precipitation to their summa (Figure 1). Maximum duration of series has been taken 7 days. Such series of the ratios (coefficients) is named by "fragment".

Example of such fragment is represented on the Figure 1. All fragments were combined in respect to their maximum values.

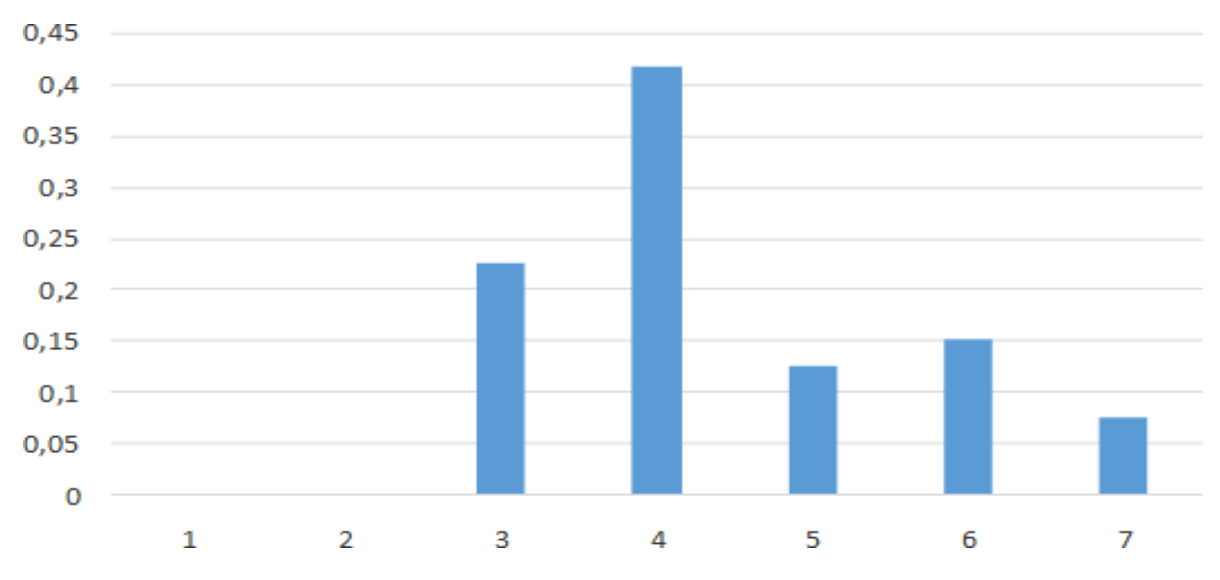

Figure 1: Example of fragment

Simulation of the artificial time series was done with help of the Fragment way of Monte Carlo method. The method uses twice modeling. At first, the ranks of summa of precipitation for the several days were modeled by method Monte Carlo. Then within series of days - daily values were modeled with help fragments, which were selected randomly (Monte Carlo method was used again). Probabilities of summa of precipitation for the several days were modeled within interval $[0-1]$ according to formula (1):

$$
P_{i+1}=0.5+(\xi *[i]-0.5)
$$

where:

$i$ - number for series of days with precipitation for artificial long time series $\left[\mathrm{i}=1-i_{\text {end }}\right]$

$i_{\text {end }}-$ total amount the series;

$\xi *[i]$ - the independent casual values which are modeled according to equal-distributed low within interval $[0-1]$; 
Evaluation and Stochastic Simulation of Storm Precipitation for City Underground ...A. Cavalli et al.

Then modeled daily precipitation. At first number of fragment was chosen how random value. Coefficients of fragment multiplied on the modeled random value of summa of precipitation for the seven days. So 1000 scenarios of storm precipitation were modeled.

\section{Result and discussion}

At first, an analysis was made in respect to changes for values and for frequency of storm precipitations. Graph of fluctuations in annual maxima of daily precipitation is represented on Figure 2. We can see that there is positive trend during data observation. Additionally Mann Kendall non parametric test [4] was used for estimation of trend, its mean was much more zero 173, such fact proofs positive trend in respect to time. The points of empirical probability on the Figure 3 confirm the increasing of maxima daily precipitation in respect to time since the points of period from 1983 until 2013 are located upper.

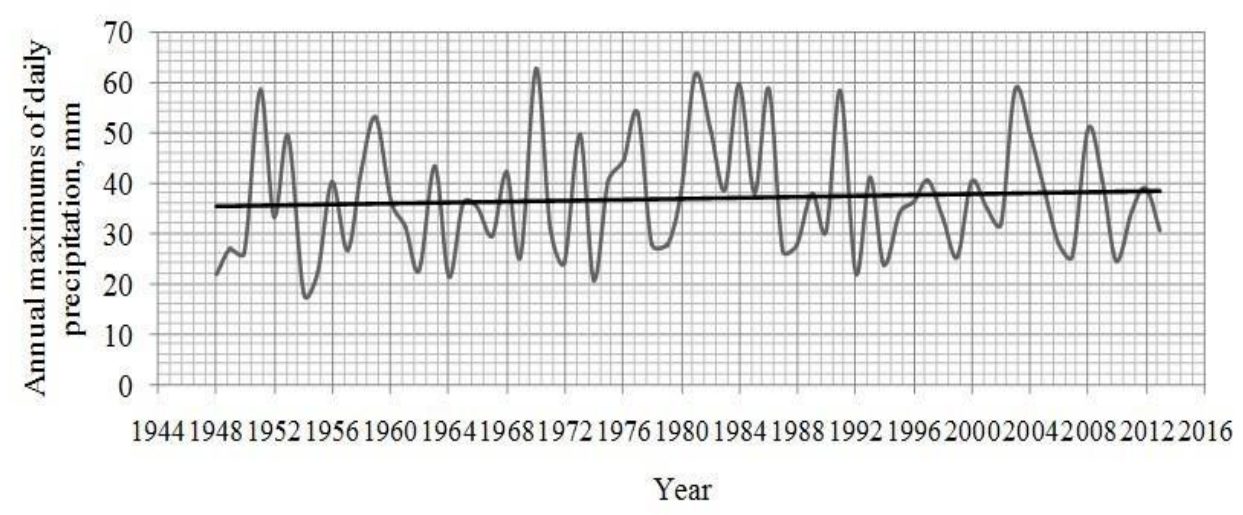

Figure 3: Graph of fluctuations in annual maxima of daily precipitation

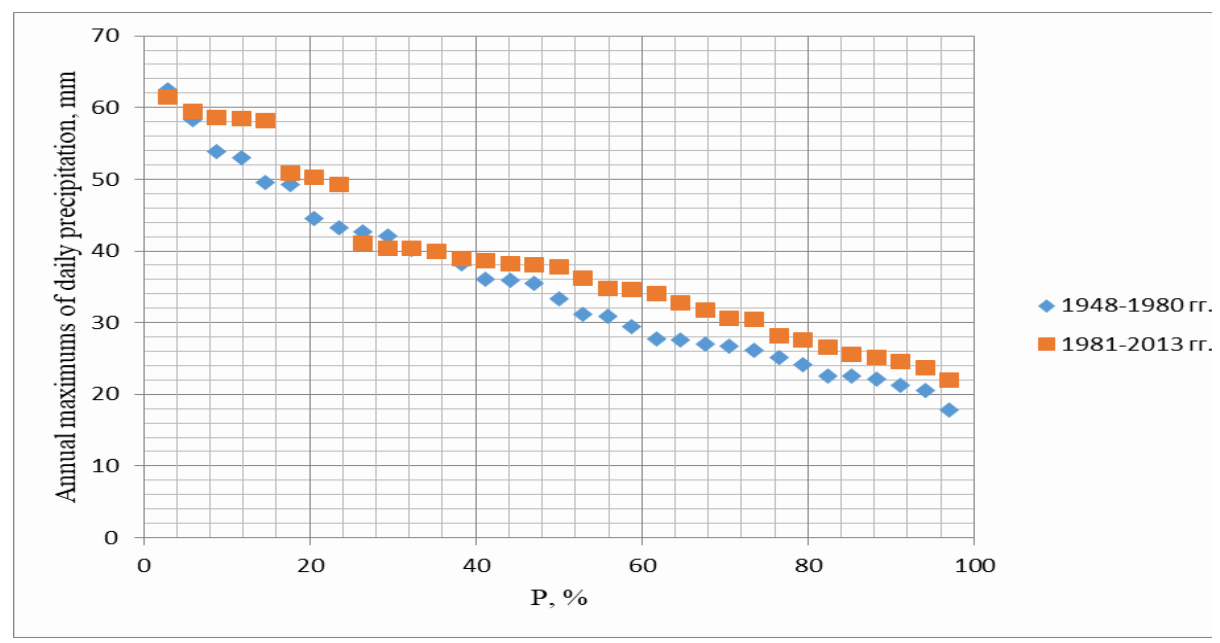

Figure 2: Graph of fluctuations in annual maxima of daily precipitation 
Evaluation and Stochastic Simulation of Storm Precipitation for City Underground ...A. Cavalli et al.

An analysis of frequency of storm precipitation was made on the base of the second statistical row $[2,3,6]$. We can see on Figure 4 that amount of cases when daily precipitation exceeds dangerous value - $30 \mathrm{~mm}$ more for last period.

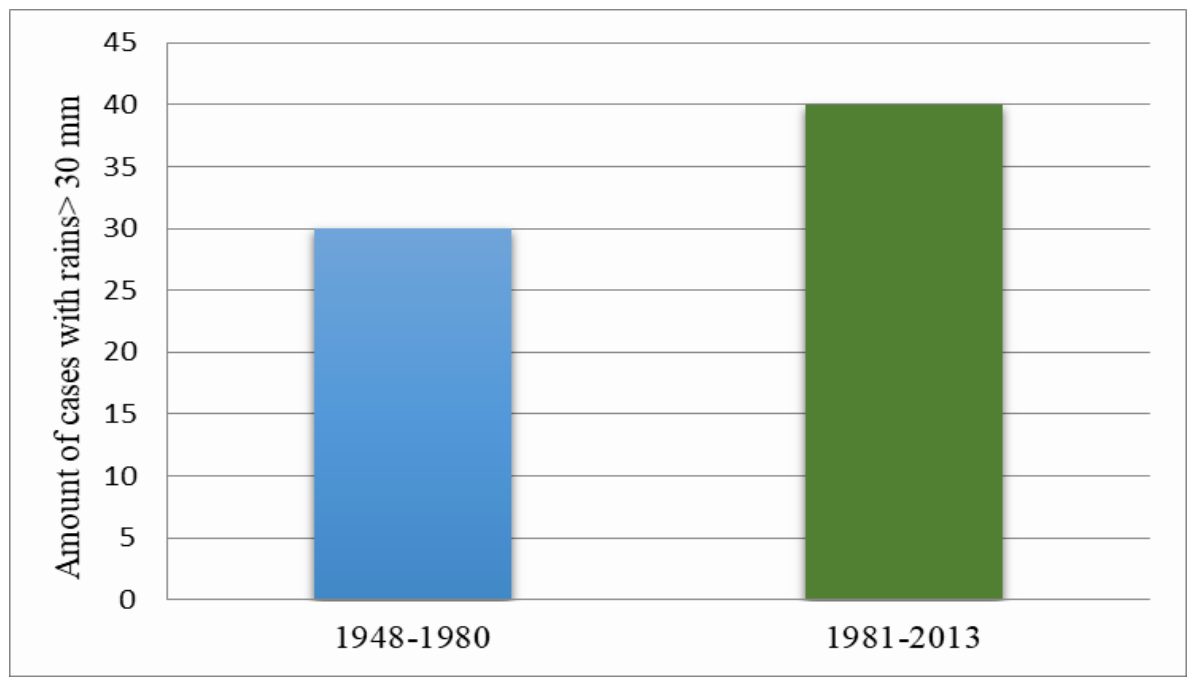

Figure 4: Amount of cases with rains $>30 \mathrm{~mm}$

Table 1 and Table 2 contain obtained statistical characteristics of modeled scenarios of dangerous periods of storm precipitations and of observed data. We can see that differences between their values are not significant.

Table 1: Comparison of averages

\begin{tabular}{cccccccc}
\hline Days & 1 & 2 & 3 & 4 & 5 & 6 & 7 \\
\hline Model & 0,83 & 4,82 & 7,93 & 36,78 & 9,81 & 3,41 & 1,21 \\
Observation & 0,71 & 4,33 & 9,03 & 33,58 & 9,72 & 2,95 & 0,87
\end{tabular}

Table 2: Comparison of $\mathrm{Cv}$

\begin{tabular}{cccccccc}
\hline Days & 1 & 2 & 3 & 4 & 5 & 6 & 7 \\
\hline Mode1 & 3,48 & 1,56 & 1,07 & 0,41 & 0,99 & 1,63 & 3,57 \\
Observation & 3,33 & 1,63 & 1,08 & 0,48 & 1,02 & 1,85 & 3,79
\end{tabular}


Evaluation and Stochastic Simulation of Storm Precipitation for City Underground ....A. Cavalli et al.

Values and frequency of storm precipitation are increasing during time in Moscow city region.

The offered special method of Monte-Carlo for simulation of scenarios of dangerous storm precipitation is adequate in respect to observation data for Moscow city conditions. The obtained scenarios can serve for modeling of maximum runoff.

\section{Reference}

Groisman, P.Y., Knight R.W., Easterling T.R., Hegerl G.C., Razuvaev V.N. (2005): Trends in intense precipitation in the climate record. J. Climate, 18, pp. 1326-1350.

V. Ilinich, E. Akulova, V. Belchihina and K. Ponomarchuk. Estimation of Statistical Characteristics for Storm Precipitation with Long-term Data to Assess Climate Change. Journal of Climate Change, Vol. 2, No. 2 (2016), pp. 83-87.

V.V. Ilinich, T.D. Larina. Evaluation of changes storm Precipitation during century for the modeling of floods. In the book: Sustainable Hydraulics in the Era of Global Change - Erpicum et al. (Eds.) C 2016 Taylor \& Francis Group, London, ISBN 978-1-138-02977-4, pp. 928 - 934.

Mann, N.B. 1945. Non-parametric test against trend. Econometrica. pp.245-259.

Sen Roy S. (2009). A spatial analysis of extreme hourly precipitation patterns in India. International journal of climatology. Volume 29, Issue 3, pp. 345-355.

Statistical methods in the Atmospheric Sciences. (2011)/Ed. R. Dmowska, D. Hartman, H.T. Rossby / Inter. Geoph. Series, Oxford, OX51GB, UK.Vol.1: 668 p.

Wilks D.S. (1999): Inter annual variability and extreme-value characteristics of several stochastic daily precipitation models. - Agricultural and Forest Meteorology. 93(3):153-169. 